3

12

3

4

5

6

7

8

For publication consideration in Industrial Crops and Products

\title{
Host plant preference of Lygus hesperus exposed to three desert-adapted industrial crops
}

James R. Hagler ${ }^{\mathrm{a}}$, Erica E. Tassone ${ }^{\mathrm{a}}$, Terry A. Coffelt ${ }^{\mathrm{a}}$, and Alexander E. Lipka ${ }^{\mathrm{b}}$

${ }^{\mathrm{a}}$ USDA-ARS, Arid-Land Agricultural Research Center, 21881 North Cardon Lane, Maricopa, AZ 85138, USA

${ }^{\mathbf{b}}$ Department of Crop Sciences, University of Illinois, Urbana, IL 61801, USA

\section{Corresponding author:}

James R. Hagler

USDA-ARS, Arid-Land Agricultural Research Center

21881 North Cardon Lane

Maricopa, AZ 85138, USA

(520) 316-6336 (office)

(602) 550-7263 (cell)

james.hagler@ars.usda.gov (e-mail)

29

(1)


31 The desert-adapted crops vernonia (Centrapalus pauciflorus), lesquerella (Physaria fendleri),

32 and camelina (Camelina sativa) are being grown in the arid southwestern USA as potential

33 feedstock for biofuel and/or other environmentally friendly products. A plant feeding choice test

34 was conducted to determine the relative attractiveness of these three "new" crops to a possible

35 insect pest, Lygus hesperus Knight. Adult L. hesperus were readily observed feeding or resting

36 on the flowering structures of each plant type, but they were seen most often on vernonia and

37 least often on camelina. Lygus hesperus readily deposited their eggs on each plant species, but again, the greatest amount of egg deposition was found on vernonia and the least on camelina.

39 These studies indicate that $L$. hesperus might pose a threat to the production of these new crops.

40 Moreover, the commercial expansion of these crops could significantly alter the population

41 dynamics of the existing arthropod community. New challenges for managing this pest during 42 regional crop production changes are discussed.

44 Keywords: Centrapalus pauciflorus, Parthenium argretatum, Physaria fendleri, Choice test, 45 Oviposition preference, Feeding preference 


\section{Introduction}

Several desert-adapted (i.e., low water and fertilizer input) industrial crops including vernonia (Centrapalus pauciflorus (Willd.)), lesquerella (Physaria fendleri (A. Gray) O'Kane \& Al-Shehbaz), and camelina (Camelina sativa (L.) Crantz) are being grown on a relatively small scale in the Southwestern USA. Vernonia is a short season crop that is cultivated in the spring and summer months. It yields high quantities of epoxy fatty acids that are useful in the reformulation of oil-based paints to reduce the emission of volatile organic compounds that contribute to the production of smog (Perdue et al., 1986). Other potential markets for the epoxy fatty acids include eco-friendly plasticizers, additives in polyvinyl chloride, polymer blends and

coatings, cosmetic, and pharmaceutical applications (Shimelis et al., 2013). The unique structure of vernolic acid may have a much wider use than epoxidized oils at about half the cost of soybean and linseed oils (Carlson and Chang, 1985). Lesquerella is a perennial mustard that is cultivated during winter and spring months (Wang et al., 2010). It is being developed as an oilseed crop for use in making eco-friendly lubricants, resins, waxes, nylons, plastics, and cosmetics (Dierig et al., 1993). Lesquerella oil can also be used for high-performance biodiesel or as an additive to diesel fuels to lessen engine damage while lowering vehicle emissions such as hydrocarbons, carbon monoxide, and particulate matter (Goodrum and Geller, 2005; Moser et al., 2008). Typically grown in the spring, camelina is a short season oil seed crop that is undergoing resurgent interest due to its potential as a biofuel feedstock (Moser and Vaughn, 2010), livestock feed (Colombini et al., 2014), and salmon feed (Hixson et al., 2014). It also yields seeds that have high concentrations of unsaturated Omega 3 fatty acids that compare favorably with other vegetable oils (Wittkop et al., 2009). 
The development of these desert-adapted crops offers many exciting new possibilities as

biofuel feedstocks, as well as potentially providing nutritional and medical products. However, their commercial development and integration into the existing agro-ecosystem, as either replacement for conventional crops (i.e., cotton or alfalfa) or as additions to a producer's cropping system, will undoubtedly influence the structure, dynamics, and function of the extant arthropod community. Of particular interest are the potential impact of arthropods on these new crops and the changes in arthropod community dynamics that may exacerbate or ameliorate pest problems in current conventional crops grown in the region.

Lygus spp. (primarily L. hesperus Knight) are regarded as a major threat to cotton and many other crops grown in the arid regions of the USA (Leigh, 1976; Leigh et al., 1988; Mauney and Henneberry, 1984; Strong, 1970). Lygus' status as a major pest is due to several factors. First, Lygus spp. are known to feed on >150 different host plants including cotton, alfalfa, canola, and many fruits, vegetables, ornamentals and weeds (Schwartz and Foottit, 1998; Young, 1986; Wheeler, 2000). Second, Lygus spp. often feed directly on the plant's young fruit, shoot tips, and seeds which cause fruit deformity or dislodgement (Mauney and Henneberry, 1984; Strong, 1970; Swezey et al., 2007). Third, Lygus bug is multivoltine, capable of having five generations per year. Fourth, they cryptically overwinter as adults and undergo a reproductive diapause. In the early spring, they become highly active and seek flowering and fruiting host plants. They tend to colonize early flowering host plants in the spring and then disperse en masse to a wide variety of crops (i.e., cotton) over the summer (Sevacherian and Stern, 1975). These highly nomadic and opportunistic feeders are capable of rapidly infesting a wide variety of crops throughout the year. Finally, their pest status is exacerbated by the fact that growers have very few tactics, outside of insecticides, available for Lygus spp. control. Unfortunately, some of these 
insecticides are broad-spectrum in activity and disruptive to the environment in general and the natural enemy and pollinator complexes in particular. Given these characteristics, Lygus spp. are poised to negate some of the major gains made in integrated pest management (IPM) over the past quarter century.

Vernonia, lesquerella, and camelina appear to be attractive to L. hesperus and other arthropods (i.e., other herbivore pests, natural enemies and pollinators) that are commonly encountered in cotton and alfalfa. However, the relative preference of $L$. hesperus to these three new crops is unknown. Therefore, the goal of this study was to characterize and quantify the feeding and oviposition preferences of L. hesperus to these three industrial crops. To this end, we conducted L. hesperus feeding and oviposition host plant choice tests in arenas containing flowering vernonia, lesquerella, and camelina plants.

\section{Materials and methods}

\subsection{Test plants and insects}

Individual vernonia, lesquerella and camelina plants were grown in a 0.5 -gallon pots containing a standard soil mixture. The plants were maintained in a greenhouse at $18^{\circ} \mathrm{C}$ (night) to $30{ }^{\circ} \mathrm{C}$ (day) and $30 \%$ relative humidity $(\mathrm{RH})$. Plants were watered as needed. A 1:1 mixture of all-purpose Scotts Miracle-Gro Excel (21-5-20) and Cal-mag Miracle-Gro ${ }^{\circledR}$ Professional (15-515) was applied $(250 \mathrm{ml} / \mathrm{plant})$ at a rate of $1 \%$ shortly after the seeded plants emerge. All plants were approximately the same size and flowering during the host preference feeding choice bioassays. The adult $L$. hesperus used in all the bioassays were obtained from colony reared on an established artificial diet (Debolt, 1982). 
A feeding choice study was conducted in enclosed arenas that contained a single vernonia,

116 lesquerella, and camelina plant. Each arena was a 61-cm tall x 35.5-cm diameter clear cylindrical

117 cage (Figure 1). The arenas were covered with a fine organdy mesh fabric to facilitate air

118 exchange. The arenas were erected within a 15 × 20-m air conditioned greenhouse at the U.S.

119 Arid-Land Agriculture Research Center, Maricopa, Arizona, USA. The greenhouse was

120 maintained at a $35: 25{ }^{\circ} \mathrm{C}$ day:night cycle and at $30 \% \mathrm{RH}$. Ten cages were erected on each of

121 three different dates (30 April, 7 May and 14 May, 2010), which served as blocks in the

122 experimental design. The arenas were put on benches at chest height to facilitate the direct focal

123 observations. The arrangement of plants within each cage was randomized. For each cage, 3 to 5

124 day-old adult $L$. hesperus ( $n=50$ per cage) were released at 14:00 at an approximate sex ratio of

125 1:1. The number and location (i.e., main stem, petioles, leaves, and flowering structures) of $L$.

126 hesperus on each plant were then recorded for the next four consecutive days at 08:00, 11:00 and

$127 \quad 14: 00 \mathrm{~h}$.

128

129

\subsection{Statistical analysis}

130 We fitted a series of mixed linear models to assess the host plant preference of L. hesperus.

131 A value of 0.5 was added to each recorded insect count to eliminate mathematical errors (i.e.,

132 taking the log transformation of zero insect counts) encountered during the process of identifying

133 the optimal model. To ensure that the data adhered to the statistical assumptions made for the

134 mixed linear model, the Box-Cox procedure (Box and Cox, 1964) was conducted, and

135 Studentized deleted residuals (Kutner et al., 2004) were examined from models that accounted

136 for plant preference, block, day, and time of day. Upon completion of these diagnostic measures,

137 it was determined that the inverse transformation (i.e., the reciprocal of insect counts) was 
optimal, and that there were no outlying observations. Subsequently, the following model was fitted to the data:

Where $Y_{i j k l m}$ is an individual observation, $\mu$ is the grand mean, Plant_Species ${ }_{i}$ is the fixed effect of $i^{\text {th }}$ plant species, Block $k_{j}$ is the random effect of $j^{\text {th }}$ block, Day $(B l o c k)_{k(j)}$ is the random effect of the $k^{\text {th }}$ day nested within the $j^{\text {th }}$ block, Time $(\operatorname{Day})_{l(k)}$ is the random effect of the $l^{\text {th }}$ time of day in which insect counts were recorded within the $k^{\text {th }}$ day, and $\varepsilon_{i j k l m}$ is the random error term.

Significant differences in the mean visitation rate on each plant species were identified by the Tukey multiple-comparison procedure (Tukey, 1953).

\subsection{Host plant oviposition preference test}

At the conclusion of each four day feeding choice experiment, the plants were cut at their base and frozen at $-20{ }^{\circ} \mathrm{C}$. Freezing the plants served two purposes: (1) it arrested egg development and (2) it facilitated the process of locating cryptically concealed eggs embedded in the plant tissue (i.e., frozen eggs are easier to spot than viable eggs, JRH, pers. obs.). After the plants had been frozen, the number and location (i.e., main stem, petioles, leaves, and flowering structures) of the eggs deposited on each host plant was identified by focal observation using a 10x dissecting microscope.

\subsection{Statistical analysis}

A similar statistical analysis to that conducted for the host plant feeding preference study was conducted for the oviposition choice tests. Briefly, a value of 0.5 was added to all egg counts, the data were subsequently subjected to the Box-Cox procedure (Box and Cox, 1964), 
161 and Studentized deleted residuals (Kutner et al., 2004) were used to screen for outliers.

162 Compared to the host plant feeding preference data, the only major difference was that these

163 procedures were conducted using models that accounted only for plant and block effects.

164 Subsequently, the egg counts were transformed to the $-0.15^{\text {th }}$ power to ensure that the data

165 adhered to the statistical assumptions of the mixed model. After these diagnostic measures had

166 been completed, the following model was fitted to the data:

167

168

$$
Y_{i j k}=\mu+\text { Plant_Species }_{i}+\text { Block }_{\mathrm{j}}+\varepsilon_{i j k}, \text { (ii) }
$$

169

Where $Y_{i j k}$ is an individual observation, $\mu$ is the grand mean, Plant_Species s $_{i}$ is the fixed effect of

$171 i^{\text {th }}$ plant species, Block $k_{\mathrm{j}}$ is the random effect of $j^{\text {th }}$ block, and $\varepsilon_{i j k}$ is the random error term.

172 Significant differences in the mean visitation rate on each plant species were identified by the

173 Tukey multiple-comparison procedure (Tukey, 1953).

174

175

176

177

178

179

180

181

182

183

184

185

\section{Results}

\subsection{Host plant feeding preference test}

There were highly significant differences in host plant preference exhibited by adult $L$. hesperus in the feeding arenas on each of the three plant species examined $(\mathrm{F}=166.36 ; \mathrm{P}<$ 0.001). Specifically, L. hesperus were observed most often on vernonia and least often on camelina (Figure 2A). The location of adult L. hesperus on each of the plant species were very similar. Specifically, the bugs were observed on the flowering structures $>$ leaf tissue $>$ petiole $>$ main stem for each of the plant types (Figure 2B). 


\subsection{Host plant oviposition preference test}

There were highly significant differences in the number of eggs deposited on each plant type $(\mathrm{F}=73.96 ; \mathrm{P}<0.001)$. Female $L$. hesperus strongly preferred vernonia $>$ lesquerella $>$ camelina (Figure 3A). In general, the L. hesperus oviposition patterns on each plant species were similar. Specifically, L. hesperus eggs were found on the petiole (except for vernonia) > flowering structures $>$ leaf tissue $>$ main stem (Figure 3B).

\section{Discussion}

Lygus hesperus and other members of the Lygus spp. complex feed and reproduce on a broad range of valuable crops (Scott, 1977). Lygus spp. are serious pests because they feed preferentially on plant reproductive tissue and cause damage with polygalacturonase, a salivary enzyme (Shackel et al., 2002). Examples of feeding damage to crops include boll damage and abscission in cotton (Mauney and Henneberry, 1978); flower "blasting”, reduced seed viability, and seed shed in alfalfa and other seed crops (Tingey and Pillemer, 1977); and fruit deformity (known as catfacing) in strawberry (Swezey et al., 2007). This feeding choice study and a nochoice plant feeding study (Naranjo and Stefanek, 2012) indicate that L. hesperus focus their feeding activity on the reproductive tissues of vernonia, lesquerella, and camelina.

Historically, cotton is a major summer crop grown in arid regions of the USA. Lygus spp. (primarily L. hesperus), whitefly (Bemisia tabaci), and pink bollworm (Pectinophora gossypiella) are regarded as the three most destructive cotton pests in this region. There has been substantial progress made over the past quarter century using the IPM approach to reduce cotton damage caused by whitefly and pink bollworm. This is due, in large part, to the integration of insect growth regulators for control of whitefly and $B t$ cotton for control of pink bollworm. In 
212 addition, cultural control tactics (e.g., strategic planting of cotton refuges for $B t$ resistance

213 management) and biological control tactics (e.g., better conservation of natural enemies) have

214 played key roles in the IPM of whitefly and pink bollworm. Unfortunately, there has not been as

215 much progress toward establishing an effective IPM program for managing L. hesperus in cotton

216 and in other arid-land crops. This is due in large part to the use of broad spectrum insecticides

217 used to control Lygus spp. and the nomadic behavior of this polyphagous pest.

218 Although there has been progress toward the IPM of two of the major cotton pests, the total

219 cotton production acreage in California and Arizona continues to decline each year (Blake, 2015)

220 due to lower prices, continued drought, and increased competition to produce higher valued

221 crops. The drop in cotton acreage will require development of alternative high cash and low

222 input crops, and therefore increased production of vernonia, lesquerella, and camelina is highly

223 likely in the near future. The introduction of new crops will undoubtedly change the agricultural

224 landscape and the arthropod population dynamics. Such a drastic change may exacerbate or

225 ameliorate crop pest problems in the region. For example, while L. hesperus is not as attracted to

226 lesquerella and camelina as vernonia, their phenologies are very different from vernonia’s.

227 Specifically, lesquerella and camelina are planted in the fall and winter and flower in the spring.

228 Conversely, vernonia is planted in the late spring and blooms during the summer. As such, a

229 significant increase in the production of lesquerella and camelina might provide an ideal

230 overwintering habitat (refuge) for Lygus spp. that could later disperse into vulnerable summer

231 crops (e.g., cotton).

232 Trap cropping has proven to be an effective cultural control tactic for managing Lygus spp. in

233 organically grown strawberry fields. For example, some strawberry producers in California

234 dedicate two percent of their farm space for strategic plantings of alfalfa (e.g., one row of alfalfa 
235 for every 50 rows of strawberry). Alfalfa (especially when it is blooming) is much more

236 attractive to Lygus spp. than strawberry (Swezey et al., 2007). This cultural control tactic lures

237 Lygus spp. away from the valuable strawberry crop and provides a favorable habitat for natural

238 enemies and pollinators (Swezey et al. 2007, 2013, 2014). Data from this study indicate that $L$.

239 hesperus exhibits a strong attraction towards vernonia's flowering structures. If vernonia can

240 attract $L$. hesperus during the summer and withstand an invasion, the crop could provide valuable

241 ecological services to the entire agroecosystem. Specifically, the vernonia could serve as a lure

242 (trap crop) for L. hesperus and as a refuge for natural enemies and pollinators.

243 Whether these desert-adapted crops go into widespread production remains uncertain. If so,

244 this study reveals that $L$. hesperus might pose a threat to the production of vernonia, lesquerella

245 and camelina and could alter the population dynamics of the entire arthropod community.

246 Further studies are needed to determine the extent of damage caused by L. hesperus on seed

247 yield and quality relative to pest density. In addition, studies are needed to determine the effect

248 of the phenology of each crop on the surrounding agroecosystem. Such basic agronomic

249 information will be essential for the successful stewardship of these crops into commercial

250 production.

251

252 


\section{Acknowledgements}

We thank Scott Machtley and Felisa Blackmer for their excellent technical assistance.

255 Mention of trade names or commercial products in this publication is solely for the purpose of

256 providing specific information and does not imply recommendation or endorsement by the U.S.

257 Department of Agriculture. USDA is an equal opportunity provider and employer.

258

259 


\section{Figure captions}

261

262 Figure 1. A Lygus hesperus feeding/oviposition choice arena containing a flowering camelina, 263 lesquerella, and vernonia plant.

264

Figure 2. (A) The average ( $\pm 95 \%$ confidence interval) number of Lygus hesperus observed on each host plant in the feeding preference arenas ( $n=360$ plants). (B) The frequency of

267 occurrence of $L$. hesperus on the various plant structures.

Figure 3. (A) The average ( $\pm 95 \%$ confidence interval) number of Lygus hesperus eggs deposited onto each host plant in the oviposition preference arenas ( $n=30$ plants). (B) The

271 frequency of occurrence of $L$. hesperus eggs on the various plant structures.

272 


\section{References}

Blake, C., 2015. Arizona cotton acreage slides 75 percent in last 22 years. Western Farm Press Daily.

Box G.E.P., Cox D.R., 1964. An analysis of transformations. J. Roy. Stat. Soc. B. Met. 26, 211252.

Carlson, K.D., Chang, S.P., 1985. Chemical epoxidation of a natural unsaturated epoxy seed oil from Vernonia galamensis and a look at epoxy oil markets. J. Amer. Oil Chem. Soc. 62, 934-939.

Colombini, S., Broderick, G.A., Galasso, I., Martinelli, T., Rapetti, L., Russo, R., Reggiani, R., 2014. Evaluation of Camelina sativa (L.) Crantz meal as an alternative protein source for ruminant rations. J. Sci. Food and Agric. 94, 736-73.

Debolt, J.W., 1982. Meridic diet for rearing successive generations of Lygus hesperus. Ann. Entomol. Soc. Am. 75, 119-122.

Dierig, D.A., Thompson, A.E., Nakayama, F.S., 1993. Lesquerella commercialization efforts in the United States. Industrial Crops and Products. 1, 289-293.

Goodrum, J., Geller, D., 2005. Influence of fatty acid methyl esters from hydroxlated vegetable oils on diesel fuel lubricity. Bio. Res. Tech. 96, 851-855.

Hixon, S.M., Parrish, C.C., Anderson, D.M., 2014. Full substitution of fish oil with camelina (Camelina sativa) oil, with partial substitution of fish meal with camelina meal, in diets for farmed Atlantic salmon (Salmo salar) and its effect on tissue lipids and sensory quality. Food Chem. 157, 51-61.

Kutner M.H., Nachtsheim C.J., Neter J., Li W., 2004. Applied Linear Statistical Models. 4th ed. McGraw-Hill, Boston, MA. 
Leigh, T.F., 1976. Detrimental effect of Lygus feeding on plants. P. 38, In: D.R. Scott and L.E. O’Keefe (eds.). Lygus Bug: Host Plant Interactions. Univ. Press of Idaho, Moscow, Idaho.

Leigh, T.F., Kerby, T.A., Wynholds, P.F., 1988. Cotton square damage by the plant bug, Lygus hesperus (Hemipera: Miridae), and abscission rates. J. Econ. Entomol. 81, 1328-1337.

Mauney, J.R., Henneberry, T.J., 1984. Causes of square abscission in cotton in Arizona. Crop Sci. 24, 1027-1030.

Moser, B.R., Cermak, S.C., Isbell, T.A., 2008. Evaluation of castor and lesquerella oil derivatives as additive in biodiesel and ultra-low sulfur diesel fuels. Energy and Fuels. 22, 1349-1352.

Moser, B.R., Vaughn, B.R., 2010. Evaluation of alkyl esters from Camelina sativa oil as biodiesel and as blend components in ultra low-sulfur diesel fuel. Bioresource Tech. 101, 646-654.

Naranjo, S.E., Stefanek, M., 2012. Feeding behavior of a potential insect pest, Lygus hesperus, on four new industrial crops for the arid southwestern USA. Ind. Crops Prods. 37, 358-361.

Perdue, R.E., Carlson, K.D., Gilbert, M.G., 1986. Vernonia galamensis, potential new crop source of epoxy acid. Econ. Bot. 40: 54-68.

Schwartz, M.D., Foottit, R.G., 1998. Revision of the Nearctic species of the genus Lygus Hahn, with a review of the Palearctic species (Heteroptera: Miridae). Associated Publishers, Gainsville, FL.

Scott, D.R., 1977. An annotated listing of host plants of Lygus hesperus Knight. ESA Bull. 23, $19-22$. 
Sevacherian, V., Stern, V.M., 1975. Movement of Lygus bugs between alfalfa and cotton. Environ. Entomol. 4, 163-165.

Shackel, K.A., de la Paz Celorio-Mancera, M., Ahmadi, H., Greve, L.C., Teuber, L.R., Backus, E.A., Labavitch, J.M., 2005. Micro-injection of Lygus salivary gland protein to simulate feeding damage in alfalfa and cotton flowers. Arch. Insect Biochem. Physiol. 58, 69-83.

Shimelis, H.A., Mashela, P.W., Hugo, A., 2013. Principal agronomic and seed oil traits in the industrial oil crop vernonia (Centrapalus pauciflorus var. ethiopica), S. Afr. J. Plant and Soil. 30, 131-137.

Strong, F.E., 1970. Physiology of injury caused by Lygus hesperus. J. Econ. Entomol. 63, 808814.

Swezey, S.L., Nieto, D.J., Bryer, J.A., 2007. Control of western tarnished plant bug Lygus hesperus Knight (Hemiptera: Miridae) in California organic strawberries using alfalfa trap crops and tractor-mounted vacuums. Environ. Entomol. 36 ,1457-1465.

Swezey, S.L., Nieto, D.J., Hagler, J.R., Pickett, C.H., Bryer, J.A., Machtley, S.A., 2013. Dispersion, distribution and movement of Lygus spp. (Hemiptera: Miridae) in trap-cropped strawberries. Environ. Entomol. 42, 770-778.

Swezey, S.L., Nieto, D.J., Pickett, C.H., Hagler, J.R., Bryer, J.A., Machtley, S.A., 2014. Spatial density and movement of the Lygus spp. parasitoid Peristenus relictus (Hymenoptera: Braconidae) in organic strawberries with alfalfa trap crops. Environ. Entomol. 43, 363-369. Tingey, W.M., Pillemer, E.A., 1977. Lygus bugs: Resistance and physiological nature of feeding injury. Bull. Entomol. Soc. Am. 23, 277-287. 
340 Tukey, J.W., 1953. The problem of multiple comparisons, Unpublished manuscript. In: The

341 Collected Works of John W. Tukey VIII. Multiple Comparisons: 1948-1983. Chapman and

$342 \quad$ Hall, New York.

343 Wang, G.S., McCloskey, W., Foster, M., Dierig, D., 2010. Lesquerella: A winter oilseed crop for

344 the Southwest. Arizona Cooperative Extension. The University of Arizona, Tucson, AZ. 4 p.

345 Wheeler, A. G., Jr., 2000. Predacious plant bugs (Miridae). pp. 657-693. In C.W. Schaefer and

346 A.R. Panizzi, [ed.], Heteroptera of Economic Importance, CRC Press, New York.

347 Wittkop, B., Snowden, R.J., Friedt, W., 2009. Status and perspectives of breeding for enhanced

$348 \quad$ yield and quality of oilseed crops for Europe. Euphytica. 170, 131-140.

349 Young, O.P. 1986. Host plants of the tarnished plant bug, Lygus lineolaris (Heteroptera:

350 Miridae). Ann. Entomol. Soc. Am. 79:747-762. 
Figure 2
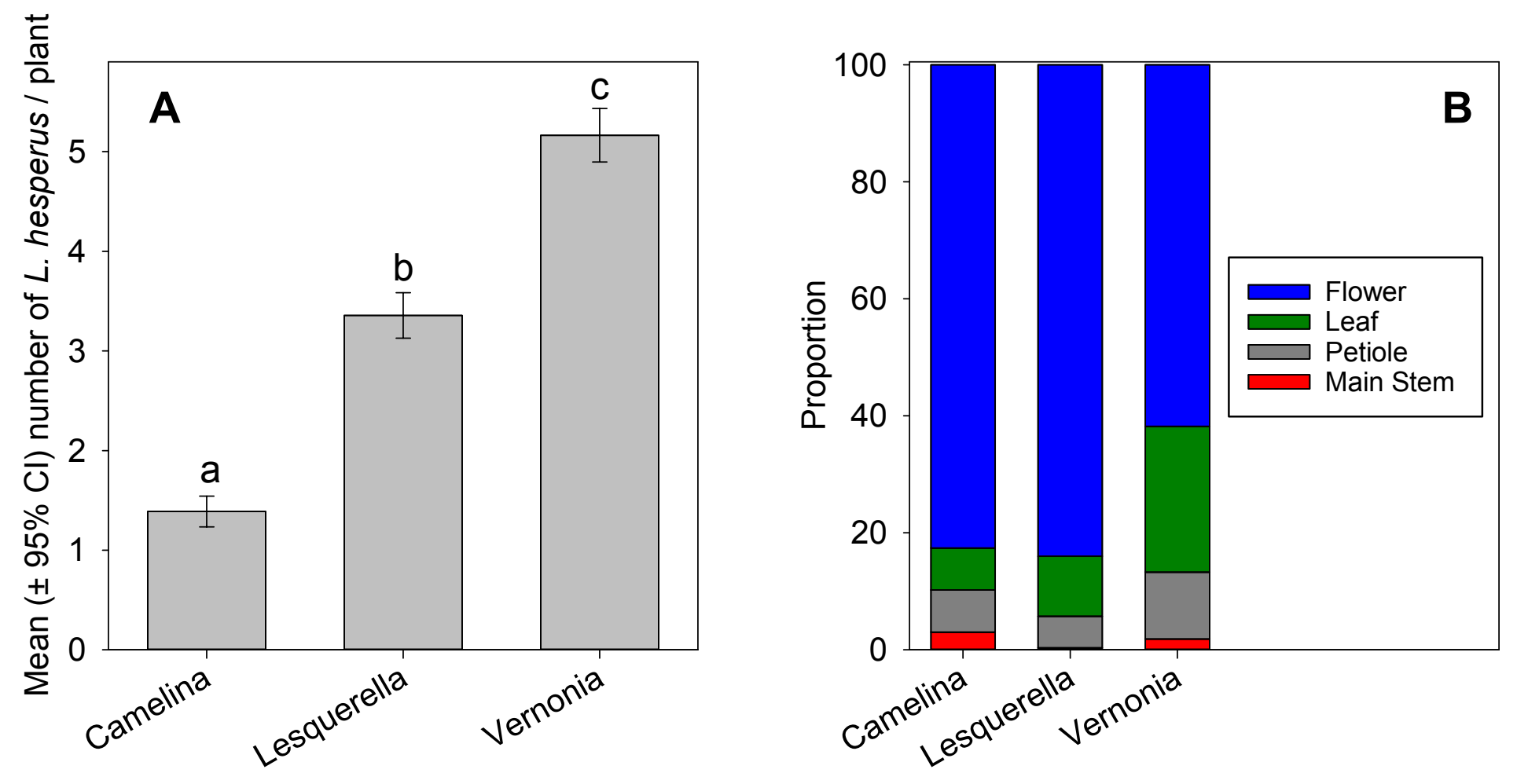
Figure 3
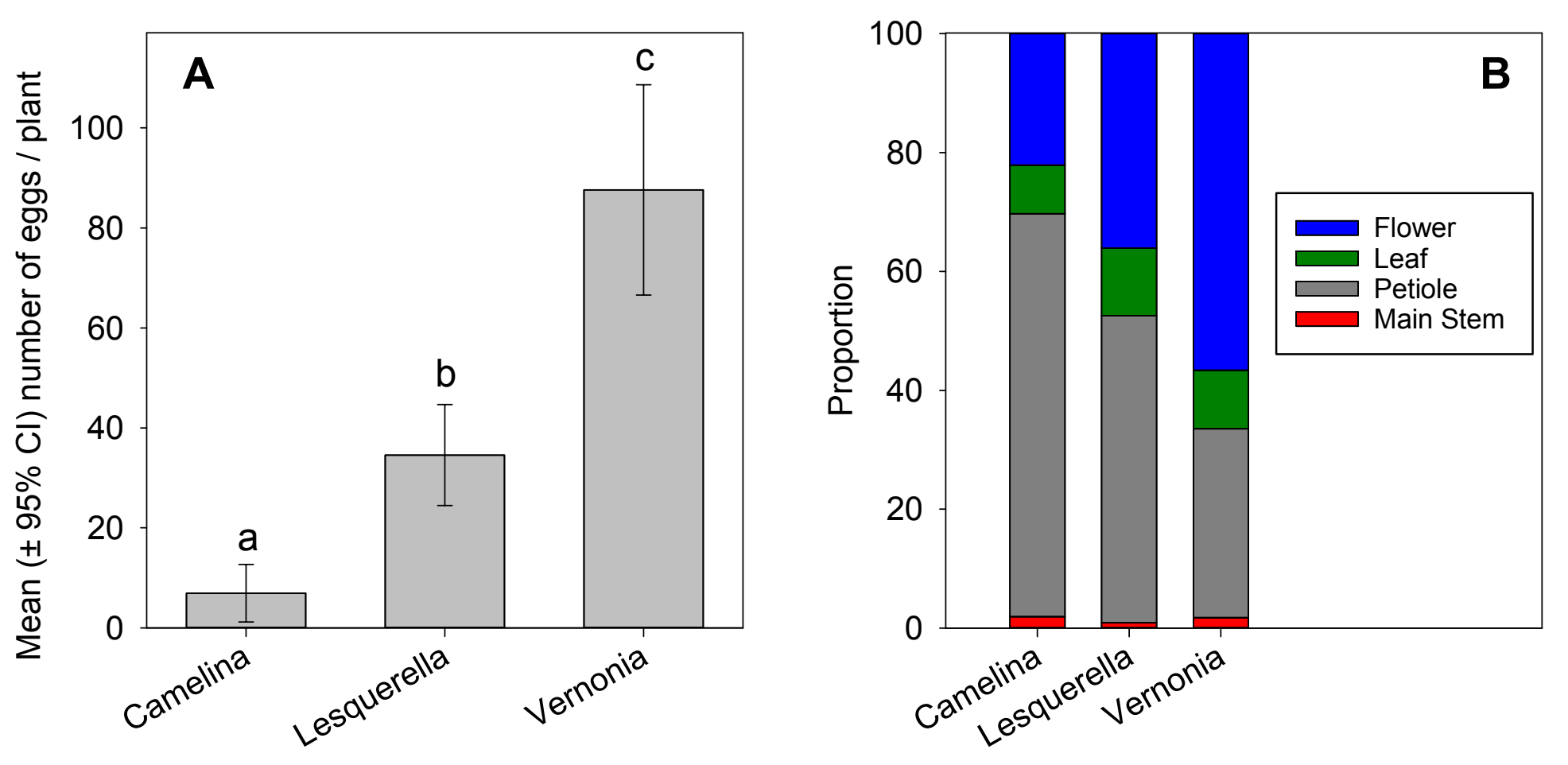